\title{
The Biologic Perturbations of Persistent Embryonic Mumps Virus Infection
}

\author{
Joseph W. St. Geme, Jr. ${ }^{[41]}$, Catherine W. C. Davis, Hugo J. Peralta, N. Elvira Farias, \\ Terry Yamauchi, and Max D. Cooper
}

Wrth the Teghnigal Assistange of Ada W. Holloway, Sandra Verrue, John A. Wankner, Robert L. DuFau, and Miriam A. Arce

\begin{abstract}
Laboratory for Microbiologic and Immunologic Research, Department of Pediatrics, Harbor General Hospital, UCLA School of Medicine, Torrance, California, and Departments of Pediatrics and Microbiology, Spain Research Laboratories, University of Alabama in Birmingham, Birmingham, Alabama, USA
\end{abstract}

\section{Extract}

A model of embryonic mumps virus infection was developed in the chicken, which allows direct study of the interaction between developing tissues and virus in the aplacental host. White leghorn and Rhode Island red embryos were inoculated with $10^{4}$ to $10^{5}$ plaque-forming units (PFU) of mumps virus between the 12 th and 16 th $\mathrm{hr}$ of incubation.

Of the total virus recovery from the organs of 11 chickens at hatch, $54 \%$ of the sum was isolated from the heart. The lung, kidney, and brain yielded $20 \%, 12.5 \%$, and $11 \%$, respectively, of the total virus isolated. Lesser amounts of virus were recovered from the liver, spleen, bursa of Fabricius, and skeletal muscle. Viremia was detected in about half of the chickens. The population of virus-producing cells in tissues ranged from 0.002 to $4.0 \%$, with the heart containing 10 -fold more infected cells than the lung, and 100-fold more infected cells than the liver and brain. Virus disappeared from the organs during the lst week after hatch. Low levels of interferon, 20 to 40 units/g, were detected in the tissues of 20-day-old infected embryos.

Intraperitoneal, intravenous, and intranasal inoculation of normal hatchling 1-, 2-, 3 -, and 4-month-old chickens with mumps virus failed to promote multiplication of virus or antibody production.

Infected embryos were often significantly stunted at hatch. In one experiment infected embryos at hatch weighed $37.5 \mathrm{~g}$ ( $\mathrm{SD} \pm 5.9$ ) versus $43.3 \mathrm{~g}$ ( $\mathrm{sD} \pm 2.4$ ) for control birds, $P<0.025$. The growth of infected hatchlings was reduced during the early weeks of life, but catch-up occurred by 1 month of age. Although spleen weights were similar to control birds, the weights of the liver $(P<0.025)$, heart $(P<0.025)$, and brain $(P<0.005)$ of infected chickens were significantly decreased at the completion of incubation.

Although capable of producing specific mumps virus-neutralizing antibody by 1 month of age, infected chickens experienced a delay in the maturation of immunoglobulin $M$ (IgM) and immunoglobulin G (IgG) synthesis. Serum specimens were obtained from 10 experimental and control chickens during the 1st year of life. The mean level of IgM (expressed as a percentage of normal adult serum pool) at I month was 31.7 (sEM \pm 2.6 ) for experimental chickens, significantly less $(P<0.005)$ than 
the level for control birds of 47.8 (SEM \pm 5.5 ). At 2 months, the levels of IgM for both groups were the same. The mean titers of $19 \mathrm{~S}$ natural rabbit erythrocytic agglutinins were also lower $(P<0.005)$ in experimental chickens, 4.86 (SEM \pm 0.75$)$, than in control chickens, 7.80 (SEM \pm 1.07 ), at 1 month of age but rose to equivalent titers by 2 months. The mean concentration of IgG was similar in both groups at 1 month, but fell significantly $(P<0.005)$ at 2 months when the level in experimental birds was 151 $\mathrm{mg} / 100 \mathrm{ml}(\mathrm{SEM} \pm 20)$ and in control birds was $415 \mathrm{mg} / 100 \mathrm{ml}$ (SEM \pm 64$)$. IgG levels remained low $(P<0.005)$ at 5 months, $384 \mathrm{mg} / 100 \mathrm{ml}( \pm 46)$ versus $550 \mathrm{mg} / 100 \mathrm{ml}$ $( \pm 73)$. At 11 months, the IgG concentrations were equivalent. In contrast, infection did not alter the normal transition from embryonic to adult hemoglobin synthesis.

\section{Speculation}

This experimental model obviates consideration of placental dysfunction as a cause of diminished embryonic growth and immunoglobulin production. Thus, virus may either directly reduce the size of cells or their rate of division in embryonic organs or alter cardiac output with consequent peripheral hypoperfusion. A more subtle disturbance of bursal cell function must occur in the absence of abundant viral replication to explain the appearance of transient dysgammaglobulinemia.

\section{Introduction}

An experimental model of embryonic mumps virus infection was developed originally in the chicken to explore a possible teratologic relationship between early embryonic infection and endocardial fibroelastosis. The relationship proved to be pathogenic rather than teratogenic. Myocarditis appeared in the older embryo, partically subsided during the 1st week after hatch, and culminated in the ultimate development of endocardial fibroelastosis at 1 year [28]. As is often true, experimental examination of the original question yielded additional interesting observations.

Because mumps virus replicated in all organs throughout embryonic life one might anticipate additional pathologic findings and perhaps anomalous biologic development and function. Indeed, significant alteration of growth and immunologic development resulted from infection of the immature embryo.

The aplacental avian model of embryonic virus infection does not offer perfect insight into the complexities of intrauterine infection of man. This model may have some biologic relevance, however, for those human infections wherein maternal viremia broaches the placenta and results in the extensive distribution of virus to many differentiating organs.

\section{Material and Methods}

\section{Eggs and Inoculation}

Embryonated eggs, obtained on occasion from Rhode Island red chickens but otherwise from the
White Leghorn species, were purchased from the Mission Laboratory Supply Farms [35] or the Kimber Farms [36]. The majority of eggs were obtained from leukosis-free flocks. Eggs were inoculated after 12-16 hr of incubation at $38^{\circ}$ with $98 \%$ relative humidity. The shell surface was sterilized with iodine and alcohol. Using a heavy nail a small hole was made in the shell in the blunt end of the egg. A no. 23-gauge needle was inserted through the shell hole and vitelline membrane into the yolk, up to the hub of the 1-inch shaft, and $0.05 \mathrm{ml}$ inoculum was expelled from a tuberculin syringe. The site of inoculation was sealed with sterile, warm paraffin, and the eggs were left undisturbed until hatch.

Virus

The biologic characteristics of the Amaris strain of mumps virus used in these experiments has been described [28]. Seed pools of virus were centrifuged at $1,000 \mathrm{rpm}$ to eliminate shedding HeLa cells from culture fluids. Titrations of virus were performed in HeLa cells using an hemadsorption plaque assay [2]. Titers of virus ranged from $10^{6}-10^{7} \mathrm{PFU} / \mathrm{ml}$. Thus, the inocula of virus per egg varied from $5 \times 10^{4}$ to 5 $\times 10^{5} \mathrm{PFU}$.

Control eggs were inoculated with $0.05 \mathrm{ml}$ of spent HeLa cell culture medium. This medium was harvested from cell cultures at 4,8 , and 12 days, the same time interval for the harvest of virus seed pools. These fluids were also centrifuged at $1,000 \mathrm{rpm}$ to eliminate HeLa cells. 
Tissue Assays of Virus, Interferon, and Infectious Centers

Organs removed from individual chickens at hatch were vigorously rinsed free of blood, triturated with small volumes of chilled medium (MM) [37] in cold mortars and pestles, and the tissue suspension was centrifuged in calibrated, conical tubes at $4^{\circ}$. Leaving the tissue pack undisturbed as I part, the supernatant MM was carefully removed to another tube. A sufficient amount of fresh MM was added to bring the total volume of liquid to 9 parts. These samples were considered to be $10 \%(\mathrm{v} / \mathrm{v})$ tissue extracts ( $1 / 10$ dilutions of original tissue) and aliquoted in multiple vials for storage at $-90^{\circ}$. Subsequent serial 4 - and 10 -fold dilutions of the extracts were prepared in MM for virus assay. Dilutions were absorbed for $3 \mathrm{hr}$ at $35^{\circ}$, then rinsed off with BSS. Cultures were fed with MM and hemadsorption plaques were read after 4 days [2].

In preparation for the assay of interferon, the $\mathrm{pH}$ of the tissue extracts was reduced to 2.5 with $1 \mathrm{~N} \mathrm{HCI}$ for $18 \mathrm{hr}$ at $4^{\circ}$, then restored to pH 7.4 with $1 \mathrm{~N} \mathrm{NaOH}$. Serial two- or fourfold dilutions of the $\mathrm{pH}$-treated extracts were made in modified MM (serum, 2 volumes) and $2.5 \mathrm{ml}$ each dilution was added to flasks containing 12-day-old primary chicken embryonic cells for incubation overnight at $35^{\circ}$. The monolayers were rinsed with BSS the next day and challenged with 50 PFU of vesicular stomatitis virus (VSV). After adsorption of $0.3 \mathrm{ml} \mathrm{VSV}$ for $1.5 \mathrm{hr}$, cultures were rinsed with BSS and overlaid with MM containing $1.5 \%$ agar. The VSV plaques which developed within 2 days were stained with neutral red $(1 / 2,000)$ overnight at room temperature. Fifty percent reduction of plaques constituted the interferon endpoint. A pool of chicken interferon [38] was used to standardize the assay. Normal hatchling chicken tissues were included in the assay as a negative control. Species specificity of chicken interferon was determined in primary human embryonic fibroblasts.

Infectious center assays of trypsinized ( $0.1 \%$ trypsin) hatchling chicken organs were performed by the addition of serial 10-fold dilutions of well dispersed suspensions of individual chicken cells to HeLa cell flasks. Chicken cells were rinsed three times with MM before their addition to HeLa cells. The background of extracellular virus in the final rinse was an inconsequential $1 \%$ of the total virus detected by the infectious center technique, so treatment of cells with mumps virus antibody to prevent adsorption of free virus to the surface of uninfected chicken cells was considered unnecessary. Flasks were left undisturbed for 4 days so that the virus-producing avian cells could settle out on the HeLa monolayers and be identified subsequently as hemadsorption foci.

\section{Chickens}

After hatch experimental and control chickens were removed to separate tiers in a brooder for 1 month. The temperature was maintained at $95^{\circ}$ for the lst week then lowered to $90^{\circ} \mathrm{F}$. At 1 month of age chickens were relocated to large cages with continued segregration of experimental and control birds. The environmental temperature was $25^{\circ}$ with $45 \%$ relative humidity.

Chickens were weighed at hatch and at weekly intervals thereafter until 2-3 months of age. Heparinized blood samples were obtained from the wing vein at 1 month of age. Bleedings were performed in younger chickens with difficulty and occasionally required their sacrifice. Plasma specimens were frozen at $-20^{\circ}$.

\section{Immunoglobulin and Antibody Determinations}

Immunoglobulin levels were measured using methods described previously [30].

Neutralizing antibody titers were determined using techniques reported before [27] with the substitution of hemadsorption for cytopathology as an infectious endpoint.

\section{Hemoglobin}

The vitelline vessels of 4- -6-day-old experimental and control chicken embryos were exposed in situ and blood withdrawn by capillary action into finely drawn heparinized micropipettes.

Erythrocyte samples from individual embryos were washed three times with $0.85 \% \mathrm{NaCl}$ then hemolyzed with a double volume of distilled water and 0.5 volume toluene. Hemolysates were left overnight at $4^{\circ}$, then shaken vigorously 100 times, then centrifuged at $300 \mathrm{rpm}$ for $20 \mathrm{~min}$. Erythrocyte membranes were removed by filtration. Hemolysates were applied to the cathodal end of cellulose acetate strips immersed in an electrophoretic trough containing Tris-ethylenediaminetetraacetic acid-boric acid buffer, pH 8.8-9.0. Current of $300 \mathrm{mV}$ and $10 \mathrm{~mA}$ was applied to the system for $1.5-2.25 \mathrm{hr}$. The strips were removed and stained with Ponceau S stain, dehydrated in absolute methanol, and cleared in 10\% methanol-glacial acetic acid.

Experimental embryos used in hemoglobin assays were triturated and the presence of virus was determined as outlined above. 


\section{Histopathology}

Sagittal sections of embryos were obtained from the time of inoculation to 14 days of incubation. Thereafter, individual organs were removed. Tissues were fixed in $10 \%$ formalin and embedded in paraffin, and sections were stained with hematoxylin and eosin.

\section{Results}

\section{Husbandry and Inoculations}

During a 5-year period, consisting of approximately 40 experiments, the average hatch rate of all inoculated embryonated eggs was $30 \%$. Consistently, twice as many eggs inoculated with spent medium hatched when compared with virus-inoculated eggs. Uninoculated fertilized eggs hatched at a rate of $90 \%$.

At the outset of these experiments concern about nonspecific inhibition of virus multiplication by egg yolk was eliminated by performing a standard neutralization test. A $1 / 4$ dilution of yolk failed to neutralize mumps virus.

The most satisfactory method of inoculation involves the insertion through the blunt air-sac pole of the egg of a 1-inch, no. 23-gauge needle, up to the hub of the needle. Introducing $0.05 \mathrm{ml}$ inoculum of virus in this manner produces uniform infection of embryos with minimal lethality of $25 \%$. The inoculation of the narrow non-air sac pole of the egg with a longer 1.5inch, no. 23-gauge needle also permits $100 \%$ infection but results in greater lethality. The crucial importance of these routes of inoculation is the nontraumatic delivery of inoculum into the abundant yolk beneath the embryonic disc. Insertion of the needle into the top of the egg caudal to the disc, or perpendicularly into the side of the egg, were less successful techniques.

\section{Distribution of Virus in the Hatchling Chicken}

The quantity of virus in any single organ varied greatly from chicken to chicken (Table I). Virus was undetectable in the brain of one chicken (3), whereas the brain of another (5) contained 10,000 PFU/g tissue. Despite this variation it is apparent that the highest titers of virus at hatch were found most consistently in the heart and lung. The lowest titers of virus were found in the liver, spleen, bursa of Fabricius, and skeletal muscle. Although viremia was present in 6 of 10 hatchlings, the quantity of virus in blood was less than that detected in tissues.

In another experiment, in which the amount of virus in the heart was compared with the amount in lymphoreticular tissue, the pooled bursae and spleens from three hatchling chickens contained 10,000 and $1,900 \mathrm{PFU} / \mathrm{g}$, respectively, whereas the heart contained $40,000 \mathrm{PFU} / \mathrm{g}$. Throughout all of our experiments thymic tissue has been difficult to locate in virus-inoculated embryos, preventing determination of the amount of virus.

Because of the broad range of virus concentration in each organ it is impossible to treat the data in Table I in the usual statistical fashion. In Table II the quantitative endpoints of virus titration are expressed as the percentage of the total amount of virus recovered from each chicken which the individual organ represents. A mean of $54 \%$ of the total virus recovered was found in the heart. The lung contained a mean of $20 \%$, the kidney and brain yielded $12.5 \%$ and $11 \%$, and the liver and spleen contained $2.5 \%$ and $2.2 \%$, respec-

Table I. Distribution of mumps virus in the organs of the chicken at hatch ${ }^{1}$

\begin{tabular}{|c|c|c|c|c|c|c|c|c|c|}
\hline \multirow{2}{*}{ Chicken $^{1}$} & \multicolumn{9}{|c|}{ Mumps virus, plaque-forming units/g tissue or ml blood } \\
\hline & Blood & Brain & Lung & Heart & Liver & Kidney & Spleen & Bursa & Muscle \\
\hline 1 & 0 & 1,000 & 0 & 2,600 & 0 & 900 & 0 & 0 & 200 \\
\hline 2 & 80 & 100 & 10,000 & 80,000 & 200 & 1,200 & 800 & 50 & 0 \\
\hline 3 & 0 & 0 & 800 & 400 & 50 & 800 & 0 & 0 & 0 \\
\hline 4 & n.d. ${ }^{2}$ & 1,100 & 300 & 0 & 0 & 600 & 200 & 0 & 0 \\
\hline 5 & 220 & 10,000 & 31,000 & 120,000 & 200 & 1,000 & 800 & 500 & 2,400 \\
\hline 6 & 0 & 6,200 & 9,960 & 44,460 & 1,520 & II, 530 & n.d. & n.d. & n.d. \\
\hline 7 & 100 & 2,180 & 5,780 & 66,380 & 90 & n.d. & n.d. & n.d. & n.d. \\
\hline 8 & 100 & 3,350 & 25,380 & 233,600 & 670 & 1,120 & n.d. & n.d. & n.d. \\
\hline 9 & 100 & 250 & 33,870 & 39,190 & 11,430 & 10,460 & n.d. & n.d. & n.d. \\
\hline 10 & 30 & 1,870 & 2,030 & 1,320 & 670 & 910 & n.d. & n.d. & n.d. \\
\hline 11 & 0 & 1,970 & 196,280 & 298,690 & 4,420 & 4,220 & n.d. & n.d. & n.d. \\
\hline
\end{tabular}

${ }_{1}$ Chickens 1-5 from one experiment, chickens 6-11 from another experiment.

${ }^{2}$ n.d.: Organs were not assayed for virus. 
Table II. Recovery of mumps virus from hatchling chicken organs ${ }^{1}$

\begin{tabular}{ccccccccc}
\hline & \multicolumn{7}{c}{ Recovery of total mumps virus, \% } \\
\cline { 2 - 9 } Chicken $^{2}$ & Heart & Lung & Kidney & Brain & Liver & Spleen & Bursa & Muscle \\
\hline 1 & 56 & 0 & 19 & 21 & 0 & 0 & 0 & 4 \\
2 & 87 & 11 & 1 & 03 & 03 & 1 & 03 & 0 \\
3 & 20 & 39 & 39 & 0 & 2 & 0 & 0 & 0 \\
4 & 0 & 14 & 27 & 50 & 0 & 9 & 0 & 0 \\
5 & 72 & 19 & 1 & 6 & 03 & 1 & 03 & 1 \\
6 & 60 & 14 & 15 & 8 & 3 & n.d.4 & n.d. & n.d. \\
7 & 89 & 8 & n.d. & 3 & 03 & n.d. & n.d. & n.d. \\
8 & 89 & 10 & 0.2 & 0.7 & 0.1 & n.d. & n.d. & n.d. \\
9 & 41 & 35 & 12 & 3 & 12 & n.d. & n.d. & n.d. \\
10 & 20 & 30 & 10 & 30 & 10 & n.d. & n.d. & n.d. \\
11 & 59 & 39 & 0.8 & 0.4 & 0.8 & n.d. & n.d. & n.d. \\
Mean & 54 & 20 & 12.5 & 11 & 2.5 & 2.2 & 0 & 1 \\
\hline
\end{tabular}

1 Does not include blood.

${ }^{2}$ Chickens $1-5$ from one experiment, chickens 6-11 from another experiment.

3 Virus was detected (see Table I) but the contribution to the total sum of Virus in the chicken was negligible.

4 n.d.: Organs were not assayed for virus.

tively. In these experiments the bursa of Fabricius and skeletal muscle contributed inconsequential amounts of virus.

The hearts of 7 of 11 chickens contained $50 \%$ or more of the total virus recovered per chicken. From none of 11 chickens did pulmonary tissue yield this percentage of virus. By chi-square analysis, using this $50 \%$ endpoint, the heart contained significantly more virus than the lung $(P<0.005)$. Use of nonparametric statistics (Mann-Whitney $U$ test) revealed that recovery of virus from the heart was significantly greater than that from the lung $(P<0.01)$.

The lungs of 4 of 11 chickens yielded $20 \%$ or more of the total virus, whereas the kidneys of 2 of 10 chickens contained this percentage of virus. The difference is insignificant $(P<0.5)$. Thus, lung, kidney, and brain contributed statistically equivalent amounts of virus to the total recovered from each chicken. Analysis of the data with the Mann-Whitney $U$ test showed that a greater percentage of virus was detected in the brain than the liver $(P<0.05)$.

When organs removed at hatch were dispersed by trypsinization into populations of single cells and plated immediately in flasks of HeLa cells, the percentage of infected cells could be determined by counting the number of hemadsorption foci. Analysis of several organs from each of three chickens disclosed a wide range of infected cells from $0.004 \%$ to $4.0 \%$ (Table III). With the exception of one chicken (3), the hearts of the others contained 4- to 10-fold more infected cells than the lungs, and 100-fold more infected cells than liver and brain.

In another experiment the pulmonary tissue of five hatchling chickens was assayed for infectious centers. The lungs from three chickens contained $0.01 \%$ infected cells and the tissue from two chickens contained $0.001 \%$ infected cells.

\section{Persistence of Virus after Hatch}

Chickens were killed between 3 and 7 days after hatch. Brain, heart, lung, liver, spleen, and kidney were removed from each bird, triturated, and assayed for virus in HeLa cells. Blood samples were also tested for virus. The same tissues were obtained from older chickens at 2 and 12 months of age. Virus disappeared from chicken organs by 1 week after hatch (Table IV). Persistent viremia was observed in the one 3-day-old virus-positive chicken and one of the two 5-day-old virus-positive chickens.

\section{Specific Neutralizing Antibody Response}

Chickens were bled at hatch and during the 5 days after hatch. Older birds were studied serologically from 1 through 12 months of age. Neutralizing antibody could not be detected in the sera obtained from 11 chickens between hatch and 5 days. Two of the seronegative chickens were viremic. Viremia might interfere with the technique of antibody assay. However, routine decomplementation of serum at $56^{\circ}$ for 30 min, prior to neutralization-incubation with challenge mumps virus, destroys mumps virus.

Eight of 10 birds bled at $1,2,5$, and 12 months of age possessed neutralizing antibody, although all had been inoculated with mumps virus as 12-hour-old embryos. The geometric mean titer of neutralizing anti-

Table III. Percentage of infected cells in each organ at hatch

\begin{tabular}{cllll}
\hline \multirow{2}{*}{ Chicken } & \multicolumn{5}{c}{ Infected cells, \% } \\
\cline { 2 - 5 } & Heart & Lung & Liver & Brain \\
\hline 1 & 4.0 & 0.36 & 0.02 & 0.02 \\
2 & 0.4 & 0.09 & 0.002 & 0.004 \\
3 & 0.04 & 0.04 & 0.04 & n.d. ${ }^{1}$ \\
\hline
\end{tabular}

1 n.d.: Tissue was unsatisfactory for assay.

Table IV. Persistence of virus in chicken organs after hatch

\begin{tabular}{ccc}
\hline Age & Birds tested & Number positive \\
\hline 3 days & 2 & 1 \\
4 days & 1 & 1 \\
5 days & 4 & 2 \\
7 days & 6 & 0 \\
2 mo & 2 & 0 \\
12 mo & 5 & 0
\end{tabular}


body was maintained between $1 / 8$ and $1 / 16$ throughout the period of study.

\section{Production of Interferon}

Brain, heart, lung, liver, and kidney from six chickens were removed at hatch for assay of interferon. Ten percent suspensions of these organs contained high titers of virus (chickens $6-11$, Table I). The tissue suspensions were diluted $1 / 20,1 / 80$, and $1 / 320$. Interferon was undetectable. Thus, these tissues contained less than 200 units interferon/g.

In order to assay more concentrated tissue suspensions, the organs from several 20-day-old embryos were pooled. The hearts from three embryos, each of which contained $10^{4} \mathrm{PFU}$ mumps virus/g, yielded a pool interferon titer of 20 units $/ g$. The hearts from two additional embryos, containing $10^{4}$ and $10^{5} \mathrm{PFU}$ of virus, yielded 40 units interferon. The spleen of five embryos, each containing $10 \mathrm{PFU}$ of virus, yielded 40 units interferon. Titration of similar three-embryo pools of brain, liver, and skeletal muscle, containing 10-10 ${ }^{3}$ PFU virus, disclosed undetectable interferon or less than 20-40 units. A bursa of Fabricius pool obtained from five embryos contained less than 20 units interferon. The mean concentration of virus in the bursae was $20 \mathrm{PFU} / \mathrm{g}$. The interferon in these chicken tissues was species specific. Further biologic characterization of the interferon was impossible because of insufficient volumes of triturated tissue.

\section{Growth Retardation}

Consistently, infected chickens weighed less than control birds at hatch. The data from a representative experiment are summarized in Table $\mathrm{V}$.

In several experiments a statistically significant con-

Table $V$. Weight of hatchling chickens ${ }^{1}$

\begin{tabular}{cc}
\hline \multicolumn{2}{c}{ Weight, g } \\
\hline Control & Infected \\
\hline 46.5 & 42.5 \\
40.0 & 50.0 \\
45.0 & 39.0 \\
43.5 & 35.0 \\
43.5 & 33.5 \\
45.5 & 32.0 \\
38.5 & 31.0 \\
42.5 & 37.0 \\
45.0 & \\
42.5 & $37.5 \pm 5.9^{2}$ \\
$43.3 \pm 2.4^{2}$ &
\end{tabular}

'Student's $t$ test $P<0.025$.

2 Mean $\pm s D$.

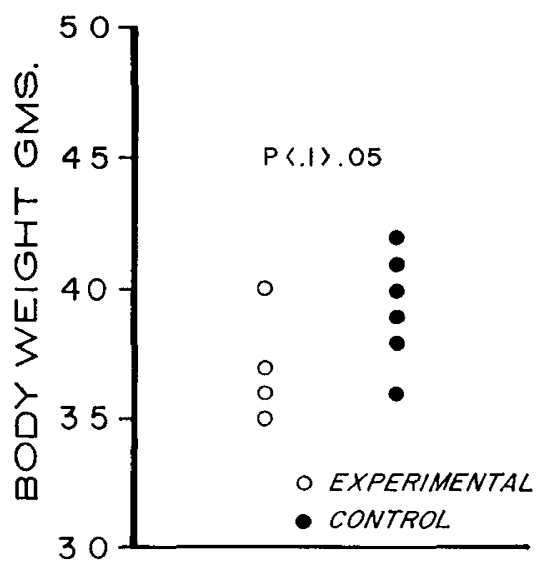

Fig. 1. Weight of infected and control chickens at hatch. The lungs of all four experimental chickens contained mumps virus. Statistics were computed by Student's $t$ test. White leghorns.
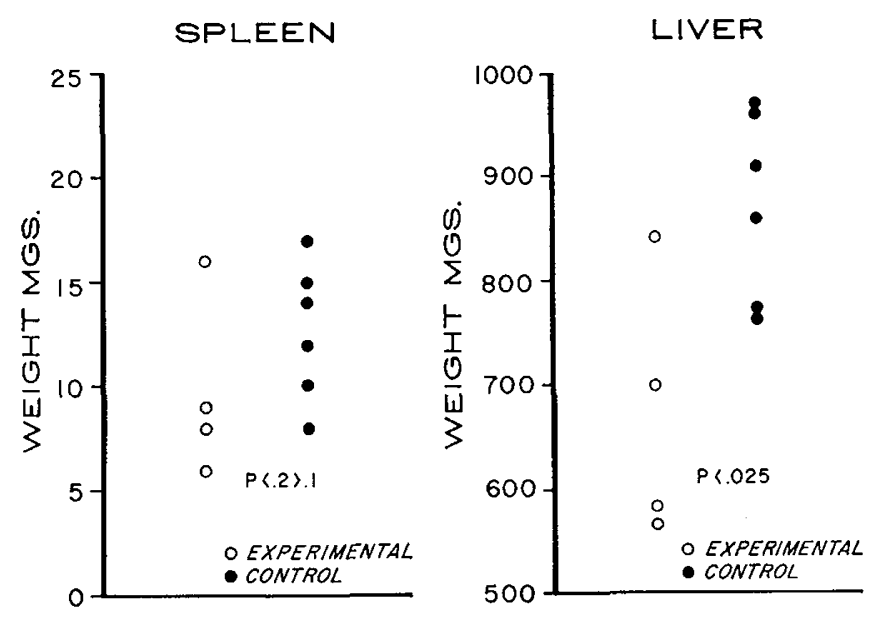

Fig. 2. Weight of spleen and liver from infected and control chickens at hatch. From the same experiment as Figure 1. Statistics computed by Student's $t$ test.

clusion could not be reached because of the small number of hatchling birds (Fig. 1). The organs were also weighed in this experiment and although the spleen weights were similar, the weights of liver, heart, and brain from infected chickens were significantly less than organs from control chickens (Figs. 2 and 3). The brain weights of experimental chickens were strikingly decreased $(P<0.005)$.

When birds were weighed at weekly intervals during the 1st month of life, the growth of experimental chickens declined for 1-2 weeks, then caught up with control chickens. In one experiment with White Leghorn chickens (Fig. 4), experimental birds weighed considerably less than controls at 8 days after hatch $(P<$ 0.005 , Student's $t$ test). At 17 days of age the difference was less obvious $(P<0.05)$. Another experiment with 


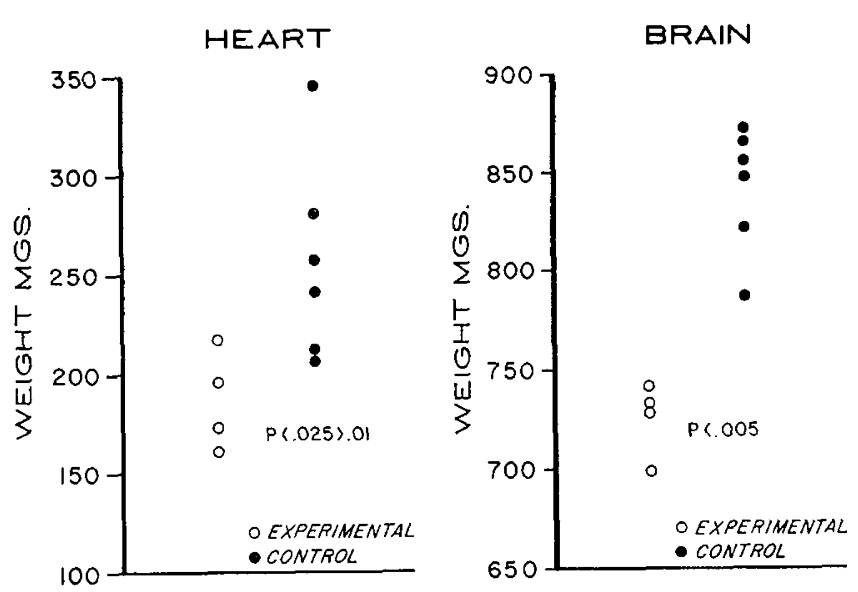

Fig. 3. Weight of heart and brain from infected and control chickens at hatch. From the same experiment as Figure 1. Statistics computed by Student's $t$ test.

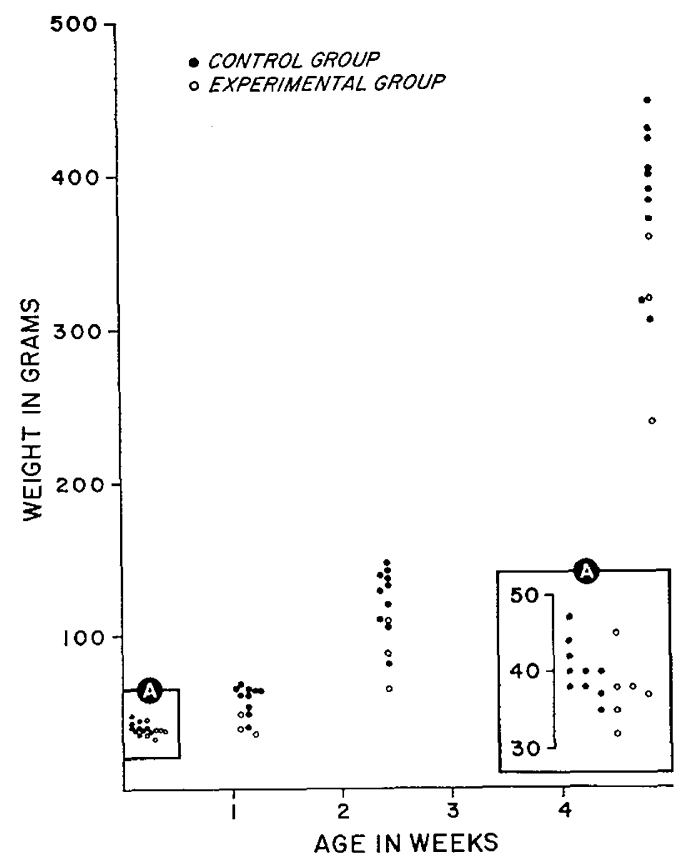

Fig. 4. Weights of experimental and control chickens throughout the first 34 days after hatch. Inset A depicts weights at hatch. White leghorn.

Rhode Island red chickens (Fig. 5) revealed a highly significant disparity in weight at 12 days of age $(P<$ $0.0005)$, which disappeared by 19 and 26 days after hatch.

\section{Development of Immunoglobulins and Natural Agglu- tinins}

One month after hatch the mean levels of IgM in the serum of experimental chickens were significantly lower than in controls $(P<0.005$, Student's $t$ test, Table VI and Fig. 6). At 2 months of age IgM production by experimental chicken had equaled that of control birds and comparable rates of IgM synthesis were sustained by both groups throughout the lst year of life (Fig. 6). Levels of natural rabbit erythrocyte agglutinin, determined to be $19 \mathrm{~S}$ by the susceptibility of agglutinin titers to 2-merceptoethanol, were also low in experimental chickens at 1 month of age $(P<$ $0.005)$, but had matched the levels in the sera of controls by 2 months (Table VI).

Persistence of maternal IgG of yolk sac origin prevents accurate evaluation of $\operatorname{IgG}$ synthesis in very young chickens. Two months after hatch a vast difference $(P<0.005)$ in the rate of IgG production was apparent between the experimental and control groups of birds. Serum IgG levels were still low in experimental chickens at age 5 months but reached normal levels by 11 months (Fig. 6).

The mumps virus-induced delay of immunoglobulin synthesis was confirmed in both White Leghorn and Rhode Island red chickens.

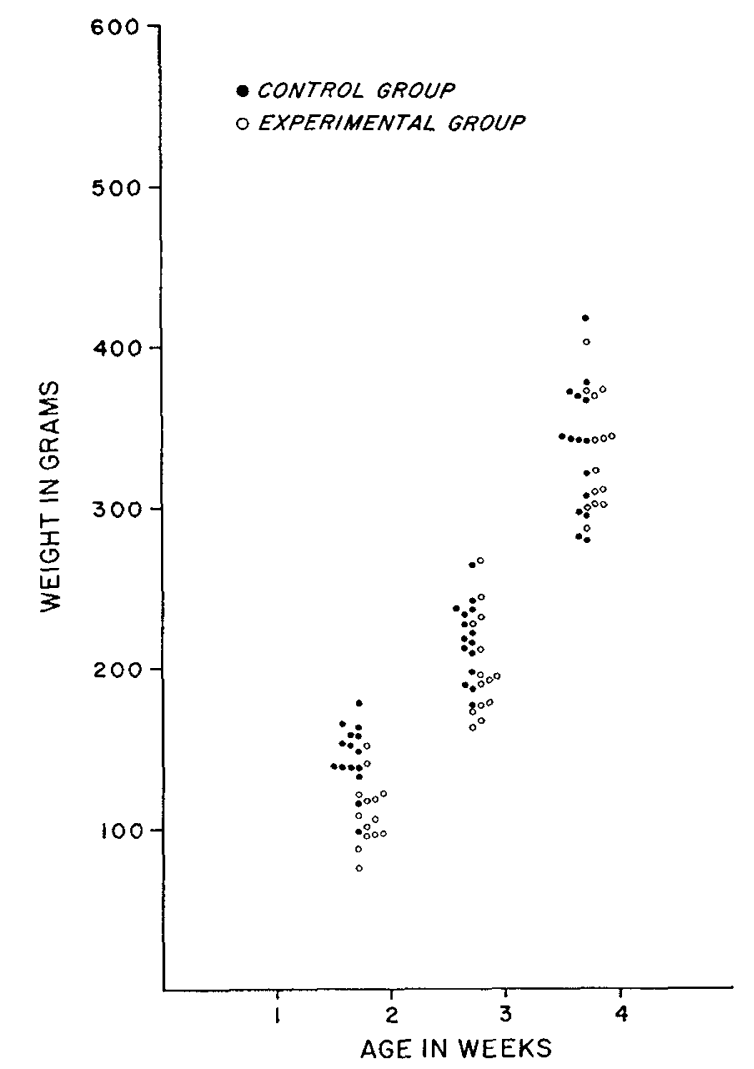

Fig. 5. Weights of experimental and control chickens throughout the 1st month after hatch. Weights were not recorded at hatch. Rhode Island reds. 
Table VI. Production of immunoglobulins and natural agglutinins during the first year of life ${ }^{1}$

\begin{tabular}{|c|c|c|c|c|c|c|}
\hline \multirow{2}{*}{ Age } & \multicolumn{2}{|c|}{ Immunoglobulin $\mathrm{M}, \%^{2}$} & \multicolumn{2}{|c|}{ Rabbit erythrocyte agglutinin ${ }^{3}$} & \multicolumn{2}{|c|}{ Immunoglobulin $\mathrm{G}, \mathrm{mg} / 100 \mathrm{ml}^{4}$} \\
\hline & Control & Expt'l. & Control. & Expt'l. & Control & Expt'l. \\
\hline $1 \mathrm{mo}$ & $47.8 \pm 5.5$ & $31.7 \pm 2.6^{5}$ & $7.80 \pm 1.07$ & $4.86 \pm 0.75^{5}$ & $137 \pm 11$ & $145 \pm 17$ \\
\hline $2 \mathrm{mo}$ & $50.7 \pm 5.0$ & $46.6 \pm 4.9$ & $10.27 \pm 0.84$ & $9.71 \pm 0.96$ & $415 \pm 64$ & $151 \pm 20^{5}$ \\
\hline $5 \mathrm{mo}$ & $48 \pm 4.4$ & $46 \pm 5.1$ & n.d. ${ }^{6}$ & n.d. & $550 \pm 73$ & $384 \pm 46^{5}$ \\
\hline $11 \mathrm{mo}$ & $81 \pm 4.6$ & $73 \pm 4.9$ & n.d. & n.d. & $712 \pm 62$ & $697 \pm 79$ \\
\hline
\end{tabular}

1 Sera from 10 control and 10 experimental chickens were assayed.

${ }^{2}$ Results expressed as a percentage of normal hyperimmunized adult chicken serum pool, \pm sEM.

3 Results expressed as $\log 2$ titer of 2 -mercaptoethanol-sensitive antibody, \pm sEM.

${ }^{4} \pm$ SEM.

${ }^{5} P<0.005$, Student's $t$ test.

${ }^{6}$ n.d.: Titers were not determined.

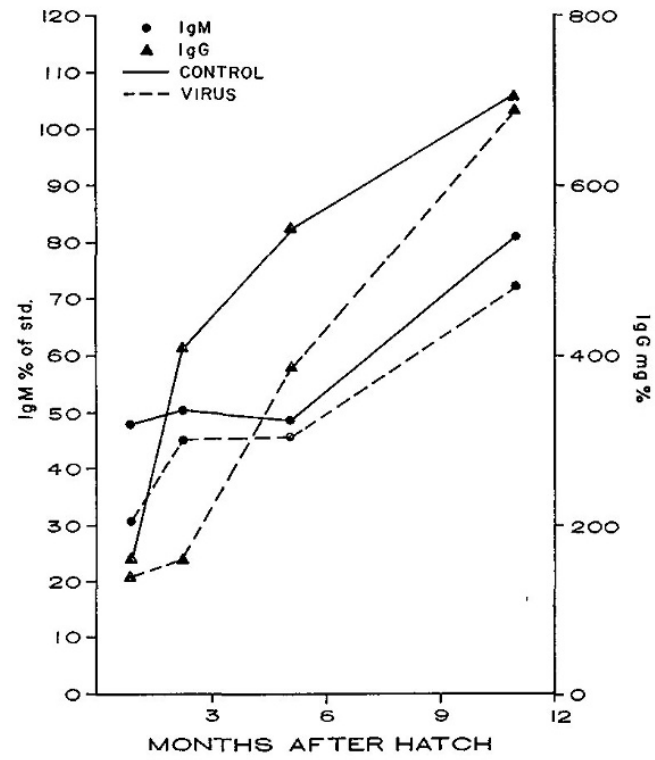

Fig. 6. Mean serum levels of immunoglobulins in experimental and control chickens throughout the 1st year of life. Rhode Island reds.

\section{Maturation of Chicken Hemoglobin}

By the 6th day of embryonic life a band of adult hemoglobin, A2S, appears on the electropherogram to the right (anodal) of the three primitive embryonic hemoglobins, $\mathrm{E}_{3}, \mathrm{E}_{2}$, and $\mathrm{E}_{1}$ (Fig. 7, left). Under normal circumstances embryonic hemoglobin $E_{3}$ disappears by the 12th day of incubation and the two additional embryonic hemoglobins are replaced by another mature hemoglobin molecule, $A_{3}$ [7]. Infection of the chicken embryo at $14 \mathrm{hr}$ of age with mumps virus did not alter the normal transition of embryonic to adult synthesis (Fig. 7, right). At hatch the two major adult hemoglobin species were present in both experimental and control chickens.

\section{Histopathology}

The bursa of Fabricius in three of five experimental chickens examined at 1 week of age contained small lymphoid follicles when compared with control birds. Bursal tissue was otherwise unremarkable during late incubation, at hatch, and at maturity when birds were necropsied. The spleens of experimental birds possessed normal lymphoid structure. The histologic appearance of the thymus was also normal, although frequently it was difficult to locate the thymus of experimental chickens.

In some experiments minimal meningeal inflammation and foci of cerebral necrosis was noted in infected

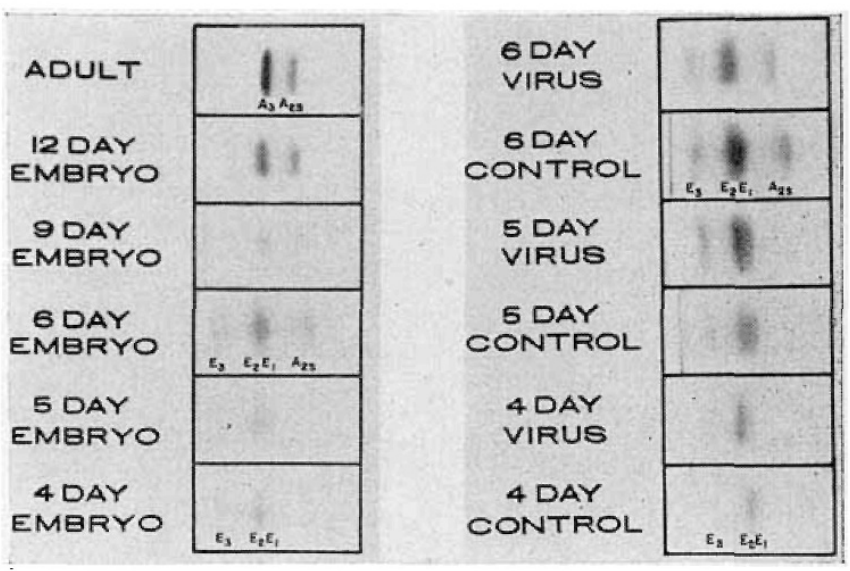

Fig. 7. Electrophoretic patterns of the maturation of embryonic and adult chicken hemoglobin. The cathodal end of the cellulose acetate strip is on the left where hemolysates were applied. Hemoglobin bands migrated to the anodal end. The strips were stained with Ponceau S stain. The panel on the left illustrates the normal transition from embryonic to adult hemoglobin. The panel on the right depicts the pattern of hemoglobin production by infected and control embryos through the critical time of transition on day 6 of incubation. 
chickens at hatch. These histologic changes persisted through the 1st week after hatch. Inflammatory infiltrate and necrobiosis was not detected in the cerebral tissue of young embryos.

\section{Susceptibility of Normal Chickens to Mumps Virus}

The inoculation of $0.5 \mathrm{ml}$ mumps virus $\left(10^{6} \mathrm{PFU}\right)$ intraperitoneally into five normal, previously uninfected chickens at hatch failed to evoke a primary neutralizing antibody response by 7 days of age. At this time virus could not be recovered from the brain, heart, lung, liver, and blood. Intraperitoneal inoculation $\left(10^{5.5}\right.$ mean infective dose $\left.\left(\mathrm{ID}_{50}\right)\right)$ of three chickens at 2 months of age failed to induce antibody production 30 days later. Three groups of six chickens were inoculated intravenously with $10^{3.5} \mathrm{ID}_{50}$ of virus at 1 , 3 , and 4 months of age, and 10 chickens, 3 months old, were inoculated intranasally with $10^{4.5} \mathrm{ID}_{50}$ of virus. One month later these birds also remained seronegative.

\section{Discussion}

There are few experimental models of persistent fetal virus infections. Perhaps the most instructive model is that of murine lymphocytic choriomeningitus virus infection [17]. Maternal infection results in the transmission of virus to the fetal host and replication of virus continues well beyond birth and into adult life $[19,32]$. The embryonic mumps virus infection which we describe in this paper persists throughout the full incubation of the chicken embryo but virus disappears from the viscera soon after hatch.

There have been many unsuccessful attempts to produce suitable models of intrauterine viral infection in the placentated host [13, 16]. Although virions may reach the placenta, they are detected infrequently in the embryo $[3,9]$. Indeed, inoculation of the natural murine host with parvoviruses result in only occasional transplacental infection [10]. Thus, the avian model represents a unique opportunity to study the relationship between the replication of virus particles in embryonic tissue and subsequent embryonic development and biologic function. The impact on embryonic development of maternal response to infection and placental dysfunction are eliminated as variables in experimental design.

Mumps virus was widely distributed in the organs of the hatchling chicken. The total amount of virus in each chicken varied considerably, like that of natural infections in other vertebrate species. Despite this vari- ation the largest percentile quantity of infectious virus, $50 \%$ or more of the total assayed in each chicken, was recovered consistently from heart tissue. The liver, spleen, and bursa contained the lowest titers of virus, usually $5 \%$ or less. Intermediate amounts of virus, $15-20 \%$ of the sum of virions per chicken, were found in the brain, lung, and kidney. The correlation between the abundance of virus and consequent pathologic changes was reasonably good. The most striking tissue destruction and inflammation is observed in the heart, with late embryonic and early hatchling myocarditis followed by a phase of healing and later the reparative changes of endocardial fibroelastosis [28]. Although observed less consistently than in the heart, minimal inflammation and necrosis also occurred in the brain.

Specific mumps virus-neutralizing antibody was present 1 month after hatch but was undetectable in serum obtained at hatch or shortly thereafter. Complexes of virus and neutralizing antibody may interfere with the detection of antibody but very few of these sera contained infectious virus. The development of specific antibody in newly hatched chickens is reminiscent of persistent fetal virus infection in humans, namely, congenital rubella and cytomegalovirus infection.

The avian model of embryonic mumps virus infection offers an interesting contrast to experimental mumps virus infection of the pregnant rhesus monkey, where virus multiplies in the monkey embryo for only a week [29]. The brevity of viral replication permits the exposure of the immature immunopoietic cells of the simian embryo to minimal antigenic mass. Consequently, the infant progeny of the intrauterine infection elaborate a more primitive, split immunologic recognition of the embryonic infection, that is, delayed hypersensitivity in the absence of sustained humoral antibody. By contrast, the continued provocation of the chicken embryo allowed sufficient antigenic exposure to induce humoral recognition of the prior infection. The very thin skin of the chicken prevented satisfactory interpretation of delayed cutaneous hypersensitivity to mumps virus. Attempts to evaluate cellular immunity by inoculating skin test antigen into the wattle of the rooster also failed.

The retardation of embryonic and post-hatch growth in infected chickens was significant. The heart and brain which contained the higher titers of virus and sustained the most obvious pathologic insult exhibited the most remarkable diminution in organ weight at hatch. The impact of this experimental embryonic infection on somatic growth and brain weight is simi- 
lar to the important sequelae of congenital rubella virus and cytomegalovirus infection in man-intrauterine growth retardation and microcephaly $[6,14,18$, 26]. The resurgence of catch-up growth, which occurs in the chicken soon after mumps virus disappears, has also been observed with the congenital rubella syndrome [14].

Rawls and coworkers [21] determined that no more than $0.1 \%$ of the parenchymal cells from fetuses with. congenital rubella contain the virus. A greater percentage of cells from the organs of congenitally infected mice contained lymphocytic choriomeningitis virus [15]. At hatch, the major organs of the embryonically infected chicken possessed a similar population of mumps virus-producing cells. However, the heart contained $1 \%$ infected cells, fully 10-100-fold more than the other organs, confirming the distribution of virus by conventional assays of triturated tissue. Studies are underway at present to discern the effect of persistent embryonic mumps virus infection on the size and number of cells in each organ, and the ability of these cell populations to divide in a normal way. The organs of infants with congenital rubella virus infection contain a diminished number of cells and these cells multiply more slowly [18, 22].

A provocative sequela of this experimental model is the transient dysgammaglobulinemia which was not restored to normal until nearly 1 year after hatch. The lower levels of natural erythrocyte agglutinins in experimental birds followed very closely the delay in maturation of serum IgM. Despite the transient immunoglobulin deficiency, previously infected chickens were fully competent to produce specific mumps virusneutralizing antibody. Similar patterns of dysgammaglobulinemia [5, 25] and in some instances hypogammaglobulinemia [20] have been observed with congenital rubella virus infection in humans.

This maturational aberration of immunoglobulin synthesis in experimental chickens is difficult to explain since the quantity of virus in the bursa of Fabricius was low at hatch. The elimination of virus from chicken tissues occurred soon after hatch, long before IgM levels returned to normal and the transition of immunoglobulin synthesis from the IgM to IgG class had occurred [1]. The histologic appearance of the bursal structures was not striking, although the bursae of some experimental birds had fewer lymphoid cells. Nevertheless, we speculate that the maturational defect of $\mathrm{B}$ lymphocytes is mediated by the embryonic viral infection at a bursal level, inasmuch as the bursa is the source of both IgM- and IgG-producing cells. Cooper and his colleagues $[1,11,12]$ have studied this maturational sequence incisively and demonstrated that late bursectomy can induce dysgammaglobulinemia with normal levels of IgM but low levels of IgG. They have suggested that within the bursa, IgGproducing cells arise from cells which had previously synthesized IgM. Because many single bursal cells contain both $\operatorname{IgM}$ and IgG (although this is rare in the spleen), the developmental switch from IgM to IgG synthesis may be confined to the bursa. The normal maturation of hemoglobin proteins in the infected embryo argues against damage at the level of a multipotent stem cell.

The rapid disappearance of virus after hatch may be explained by the development of neutralizing antibody, although antibody was not detected until 1 month after hatch. A close temporal relationship between the presence of antibody and the disappearance of mumps virus was observed with experimental infection of the pregnant monkey [29]. When maternal $7 \mathrm{~S}$ neutralizing antibody appeared, presumably capable of transplacental distribution, virus could no longer be found in the monkey embryo. Because of low titers and inconsistent distribution in tissues, interferon may not play a significant role in the control of viral replication in either experimental model of embryonic infection.

Experimental mumps virus infection of the chicken embryo has been investigated in the past $[4,23,31,33]$, but the observation of viral replication throughout full incubation and the early phase of life is unique. In the study of Williamson et al. [33], it is of more than passing interest that the two longest surviving embryos, 14 and 17 days of incubation, were markedly stunted in size. Watson [31] reported the intriguing finding that the 16-day-old chicken embryo is resistant to infection with this virus. We have been able to confirm this developmental resistance with the observation that normal hatchling and young chickens are also resistant to mumps virus infection.

Herpes simplex, vaccinia, influenza, and Newcastle disease viruses cause significant lesions in the primitive structures of the brain, spinal cord, eye, ear, and heart of the early chicken embryo $[8,24,34]$. Large inocula of virus are required to produce these teratogenic defects and are usually lethal to the embryo. Continued replication of these viruses throughout embryonic life and hatch has not been observed. Smaller inocula of virus might convert these models into provocative ex- 
amples of the more subtle impact of sublethal, persistent embryonic infection on subsequent biologic development.

\section{Summary}

A model of embryonic mumps virus infection was developed in the chicken which would permit direct study of the interaction between developing tissues and virus in the aplacental host. The very immature embryo was exposed to virus during the first $24 \mathrm{hr}$ of incubation. Virus persisted in all organs throughout incubation but disappeared during the 1st week after hatch. At hatch the greatest concentration of virus was detected in the heart. Viremia was also present at this time and infected tissues contained low levels of interferon. The population of virus-producing cells in tissues ranged from 0.002 to $4.0 \%$. After hatch, normal chickens were found to be insusceptible to mumps virus.

Infected chicken embryos were often stunted at hatch. If not disparate in size at hatch, the growth of infected hatchlings was reduced during the early weeks of life but catch-up occurred by 1 month of age. The weight of the brain and heart of infected chickens was decreased significantly at the completion of incubation.

Although capable of producing specific mumps virus-neutralizing antibody by 1 month of age, infected chickens experienced a delay in the maturation of immunoglobulin $M$ and $G$ synthesis. Normal levels of $\mathrm{IgM}$ and $19 \mathrm{~S}$ natural erythrocyte agglutinins evolved by 2 months, and normal levels of IgG appeared by 11 months. Infection did not alter the normal transition from embryonic to adult hemoglobin synthesis.

Similar to persistent viral infections of the human fetus, continued replication of mumps virus in the chicken embryo disturbs normal biologic development.

\section{References and Notes}

1. Cain, W. A., Cooper, M. D., Van Alten, P. J., and Good, R. A.: Development and function of the immunoglobulinproducing system. II. Role of the bursa in the development of humoral immunological competence. J. Immunol., 102: 671 (1969).

2. Davrs, C. W. C., and St. Geme, J. W., JR.: A rapid hemadsorption plaque assay for mumps virus. Proc. Soc. Exp. Biol. Med., 136: 1319 (1971).

3. Ferm, V. H., and Kulham, L.: Mumps virus infection of the pregnant hamster. J. Embryol. Exp. Morphol., 11: 659 (1963).

4. HABEL, K.: Cultivation of mumps virus in the developing chick embryo and its application to studies of immunity to mumps in man. Pub. Health Rep., 60: 201 (1945).
5. Hancock, M. P., Huntley, C. C., ANd Sever, J. L.: Congenital rubella syndrome with immunoglobulin disorder. J. Pediat., 72: 636 (1968).

6. Hanshaw, J. B.: Cytomegalovirus complement-fixing antibody in microcephaly. New Engl. J. Med., 275: 476 (1966).

7. Hashimoto, K., AND WILT, F. H.: The heterogeneity of chicken hemoglobin. Proc. Nat. Acad. Sci. U.S.A., 56: 1477 (1966).

8. Heath, H. D., Shear, H. H., Imagawa, D. T., Jones, M. H., AND ADAms, J. M.: Teratogenic effects of herpes simplex, vaccinia, influenza-A (NWS), and distemper virus infections on early chick embryos. Proc. Soc. Exp. Biol. Med., 92: 675 (1956).

9. Johnson, K. P.: Mouse cytomegalovirus: Placental infection. J. Infect. Dis., 120: 445 (1969).

10. Kilham, L., and Margolis, G.: Fetal infections of hamsters, rats, and mice induced with the minute virus of mice (MVM). Teratologia, 4: 43 (1971).

11. Kincade, P. W., And Cooper, M. D.: Development and distribution of immunoglobulin-containing cells in the chicken. J. Immunol., 106: 371 (1971).

12. Kincade, P. W., Lawton, A. R., Bockman, D. E., And Cooper, M.D.: Suppression of immunoglobulin $G$ synthesis as a result of antibody-mediated suppression of immunoglobulin $\mathbf{M}$ synthesis in chickens. Proc. Nat. Acad. Sci. U.S.A., 67: 1918 (1970).

13. Medearrs, D. N., JR.: Mouse cytomegalovirus infection. III. Attempts to produce intrauterine infections. Amer. J. Hyg., 80: 113 (1964).

14. Michaels, R. H., And Kenny, F. M.: Postnatal growth retardation in congenital rubella. Pediatrics, 43: 251 (1969).

15. Mrms, C. A.: Immunofluorescence study of the carrier state and mechanism of vertical trarsmission in lymphocytic choriomeningitis virus infection in mice. J. Pathol. Bacteriol., 91: 395 (1966).

16. Mrms, C. A.: Pathogenesis of viral infection of the fetus. Progr. Med. Virol., 10: 194 (1968).

17. Mims, C. A.: Effect on the fetus of maternal infection with lymphocytic choriomeningitis (LCM) virus. J. Infect. Dis., 120: 582 (1969).

18. Naeye, R. L., and Blanc, W.: Pathogenesis of congenital rubella. J. Amer. Med. Ass., 194: 1277 (1965).

19. Oldstone, M. B. A., And Dixon, F. J., Persistent lymphocytic choriomeningitis viral infection. III. Virus-antiviral antibody complexes and associated chronic disease following transplacental infection. J. Immunol., 10.5: 829 (1970).

20. Plotkin, S. A., Klaus, R. M., and Whitely, J. P.: Hypogammaglobulinemia in an infant with congenital rubella syndrome; failure of 1 -adamantanamine to stop virus excretion. J. Pediat., 69: 1085 (1966).

21. Rawls, W. E., Desmyter, J., And Melnick, J. L.: Virus carrier cells and virus-free cells in fetal rubella. Proc. Soc. Exp. Biol. Med., 129: 477 (1968).

22. Rawls, W. E., AND MELNICK, J. L., Rubella virus carrier cultures derived from congenitally infected infants. J. Exp. Med., 123: 795 (1966).

23. Robertson, G. G., Williamson, A. P., and Blattner, R. J.: Origin and development of lens cataracts in mumps-infected chick embryos. Amer. J. Anat., 115: 473 (1964).

24. Robertson, G. G., Wrlliamson, A. P., Blattner, R. J. And 
SrMONSEN, L.: The origin of cardiac lesions in early chick embryos infected with the Roakin strain of Newcastle disease virus (NDV). Anat. Rec., 133: 455 (1969).

25. Schimke, R. N., Bolano, C., AND Kirkpatrick, C. H.: Immunologic deficiency in the congenital rubella syndrome. Amer. J. Dis. Child., 118: 626 (1969).

26. Starr, J. G., BART, R. D., JR., AND Gold, E.: Inapparent congenital cytomegalovirus infection. New Engl. J. Med., 282: 1075 (1970).

27. St. Geme, J. W., JR., Noren, G. R., and Adams, P., Jr.: Proposed embryopathic relation between mumps virus and primary endocardial fibroelastosis. New Engl. J. Med., 275: 339 (1966).

28. St. Geme, J. W., JR., Peralta, H., Fardas, E., Davis, C. W. C., AND NOREN, G. R.: Experimental gestational mumps virus infection and endocardial fibroelastosis. Pediatrics, 48: 821 (1971).

29. St. Geme, J. W., Jr., Peralta, H., and Van Pelt, L. F.: Intrauterine infection of the rhesus monkey with mumps virus: Abbreviated viral replication in the immature fetus as an explanation for split immunologic recognition after birth. J. Infect. Dis., 126: 249 (1972).

30. Van Meter, R., Good, R. A., And Cooper, M. D.: Ontogeny of circulating immunoglobulins in normal, bursectomized and irradiated chickens. J. Immunol., 102: 370 (1969).

31. Watson, B. K.: Fate of mumps virus in the embryonated egg as determined by specific staining with fluorescein-labelled immune serum. J. Exp. Med., 96: 653 (1952).

32. WeIGAND, H., AND Hotchin, J.: Studies of lymphocytic choriomeningitis in mice. II. A comparison of the immune status of newborn and adult mice surviving inoculation. J. Immunol., 86: 401 (1961).

33. Williamson, A. P., Blattner, R. J., and Simonsen, L.: Cataracts following mumps virus in early chick embryos. Proc. Soc. Exp. Biol. Med., 96: 224 (1957).

34. Williamson, A. P., ANd Simonsen, L.: Specific organ defects in early chick embryos following inoculation with influenza A virus. Proc. Soc. Exp. Biol. Med., 92: 334 (1956).

35. Downey, Calif.

36. Pomona and Fremont, Calif.

37. Heat-inactivated bovine fetal serum, 5 volumes, and Hanks' balanced salt solution (BSS) supplemented with Eagle's basal medium, 95 volumes plus penicillin $(100 \mathrm{i} . \mathrm{u} . / \mathrm{ml})$ and streptomycin $(100 \mu \mathrm{g} / \mathrm{ml})$.

38. Chick reference interferon, obtained from Research Reference Reagents Branch, National Institute of Allergy and Infectious Disease, Bethesda, Md.

39. Drs. H. J. Peralta and N. E. Farias are Ford Foundation Fellows in Reproductive Biology. Dr. T. Yamauchi is a United States Public Health Service Postdoctoral Fellow in Infectious Diseases and Microbiology.

40. This research was supported by the American Heart Association, Long Beach Heart Association, United States Public Health Service (General Research Support Grant and Training Grants in Reproductive Physiology and Infectious Diseases and Microbiology), and the Ford Foundation.

41. Requests for reprints should be addressed to: JOSEPH W. Sr. Geme, JR., Department of Pediatrics, Harbor General Hospital, UCLA School of Medicine, Torrance, Calif. 90509 (USA). 42. Accepted for publication January 4, 1973. 